\title{
Controle de Plantas Daninhas pelo amicarbazone Aplicado na Presença de Palha de Cana-de-Açúcar ${ }^{1}$
}

\author{
Weed Control by Amicarbazone Applied in the Presence of Sugar-Cane Straw \\ NEGRISOLI, E. ${ }^{2}$, ROSSI, C.V.S. ${ }^{3}$, VELINI, E.D. ${ }^{4}$, CAVENAGHI, A.L. ${ }^{5}$, COSTA, E.A.D. ${ }^{6}$ e \\ TOLEDO, R.E.B.
}

\begin{abstract}
RESUMO - Considerando que a palha pode alterar a dinâmica e a eficácia dos herbicidas no sistema de cana-crua e complementar a ação destes, o objetivo deste trabalho foi verificar a eficácia do amicarbazone no controle de plantas daninhas presentes em variadas circunstâncias, incluindo a possibilidade de absorção do herbicida diretamente da palha de cana-de-açúcar. Para isso, conduziu-se um experimento em vasos com quatro repetições, em que, além das testemunhas com e sem palha, o amicarbazone foi aplicado em diferentes situações: sobre $5 \mathrm{t} \mathrm{ha}^{-1}$ de palha; sobre o solo posteriormente recoberto com $5 \mathrm{t} \mathrm{ha}^{-1} \mathrm{de}$ palha; sobre o solo sem cobertura de palha e com ou sem simulação de distintas quantidades de chuva aplicada antes ou após aplicação do produto. A dose de amicarbazone aplicada foi de $1.400 \mathrm{~g} \mathrm{ha}^{-1}$ de ingrediente ativo (i.a.), com consumo de calda equivalente a $200 \mathrm{~L} \mathrm{ha}^{-1}$. As plantas daninhas utilizadas foram Brachiaria plantaginea, Brachiaria decumbens, Ipomoea grandifolia e Cyperus rotundus. Avaliaram-se a porcentagem de controle das plantas daninhas aos $7,14,21,28,35,42,49$ e 56 DAA, nos tratamentos em que o amicarbazone foi aplicado em pré-emergência, e aos 3,10,17, 24, 31 e 38 DAA, quando o herbicida foi aplicado em pós-emergência; a biomassa seca aos 56 ou 38 DAA; e a viabilidade dos tubérculos de C. rotundus, pelo teste de tetrazólio na última avaliação. Verificou-se que, independentemente da planta daninha avaliada, os maiores indices de controle foram alcançados quando o amicarbazone foi aplicado sobre a palha, simulando-se em seguida precipitação correspond ente a 2,5 ou $30 \mathrm{~mm}$ de chuva, e nos tratamentos em que o herbicida foi aplicado diretamente no solo desnudo ou recoberto com palha. Dessa forma, para I. grandifolia, $B$. plantaginea e $B$. decumbens, patamares mais elevados de controle foram alcançados quando o amicarbazone atingiu o solo, tanto aplicado diretamente como quando lixiviado da palha pela chuva simulada após a aplicação. Já para C. rotundus, as maiores porcentagens de controle foram observadas quando o amicarbazone foi aplicado sobre a palha, com simulação de chuva imediatamente após a aplicação, evidenciando que a lixiviação pode ser um processo fundamental para uma apropriada absorção e eficácia do herbicida avaliado.
\end{abstract}

Palavras-chave: herbicida, lixiviação, cana-crua, eficácia.

ABSTRACT - Considering that straw can alter the dynamics and effectiveness of herbicides in the raw sugar-cane system, complementing their action, this work aimed to verify amicarbazone effectiveness in controlling weed plants under various conditions, including the possibility of herbicide absorption directly from sugar-cane straw. Thus, an experiment was set up in vases with four repetitions, using controls with and without straw, besides amicarbazone applied under different situations: on 5 tha ${ }^{-1}$ of straw; on soil later covered with 5 tha l $^{1}$ of straw; on soil without straw cover and with or without simulation of different rainfall amounts applied before or after

1 Recebido para publicação em 30.1.2007 e na forma revisada em 31.8.2007.

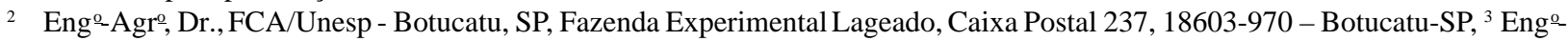
Agro , M.Sc., Doutorando em Agricultura, FCA/Unesp - Botucatu-SP, Fazenda Experimental Lageado, Caixa Postal 237, 18603970, Botucatu-SP; ${ }^{4}$ Prof., Dr., Dep. de Agricultura FCA/Unesp - Botucatu-SP; ${ }^{5}$ Prof., Dr., UNIVAG, Centro Universitário, Av. Dom Orlando Chaves, 2.655 - Cristo Rei, 78118-000, Várzea Grande-MT; ${ }^{6}$ Pesq., Dr., Unidade de Pesquisa e Desenvolvimento de Ubatuba,APTA, Rod. Oswaldo Cruz, 5061, 13680-000, Ubatuba-SP; ${ }^{7}$ Eng-Agro, Dr., Coordenador de Pesquisa e Desenvolvimento - Herbicidas, Arysta LifeScience, Rua Jundiaí, 50 - 9ª andar - Paraíso, 04001-904, São Paulo-SP. 
herbicide application. The amicarbazone rate applied was $1.400 \mathrm{~g} \mathrm{ha}^{-1}$ of active ingredient (i.a.), with equivalent liquid consumption of $200 \mathrm{~L} \mathrm{ha}^{-1}$. The weed plants used were Brachiaria plantaginea, Brachiaria decumbens, Ipomoea grandifolia and Cyperus rotundus. Weed plant control percentage was evaluated at 7, 14, 21, 28, 35, 42, 49 and 56 days after application $(D A A)$ in the treatments where amicarbazone was applied in pre-emergence and at $3,10,17,24,31$ and $38 D A A$, when the herbicide was applied in post-emergence; dry biomass was evaluated at 56 or 38 DAA as well as C. rotundus tuber viability, by applying the tetrazolium test during the last evaluation. It was verified that, regardless of the weed plant evaluated, the highest control indices were obtained when amicarbazone was applied on the straw, with a simulated rainfall corresponding to 2.5 or $30 \mathrm{~mm}$ of rain and in the treatments where the herbicide was applied directly in the soil without or with straw. Thus, for I. grandifolia, B. plantaginea and $\boldsymbol{B}$. decumbens, higher control levels were verified when amicarbazone reached the soil, both when applied directly and when leached from the straw from the simulated rainfall after application. As for C. rotundus, the highest control percentages were observed when amicarbazone was applied on the straw, with rain simulation immediately after application, showing that leaching plays a fundamental role in providing an appropriate absorption and effectiveness of the herbicide evaluated.

Keywords: herbicide, leaching, raw cane, effectiveness.

\section{INTRODUÇÃO}

Na colheita de cana-crua são deixadas sobre o solo de 5 a 20 toneladas de palha por hectare. A quantidade de palha depende diretamente das características da variedade, como facilidade de despalha do colmo, hábito de crescimento da touceira, uniformidade em altura e tamanho dos ponteiros, produtividade e desenvolvimento da cana (Manechini, 1997). A palha afeta drasticamente o estabelecimento de plantas daninhas em áreas cultivadas, de diferentes maneiras. Dentre elas, citamse a limitação de variação da temperatura na superficie do solo; a formação de uma barreira fisica a ser transposta pela planta em germinação; o aumento da quantidade de microrganismos que podem decompor as sementes destas plantas, além dos possíveis efeitos alelopáticos que inibem a germinação. Apesar disso, algumas plantas daninhas, como Ipomoea grandifolia e Euphorbia heterophylla, não têm a germinação inibida pelas quantidades de palha de cana-de-açúcar que normalmente são encontradas em campo (Martins et al, 1999; Velini \& Negrisoli, 2000; Correa \& Durigan, 2004).

Quando um herbicida é aplicado sobre a palhada, é interceptado pela superficie da palha ali depositada e torna-se vulnerável à degradação causada pela volatilização e/ou fotodecomposição, até que seja lixiviado para o solo
(Locke \& Bryson, 1997). Lamoreaux \& Hess (1993) ressaltam que a lixiviação de herbicidas da palha para o solo é dependente da capacidade desses resíduos em cobrir uniformemente o solo e reter esses agrotóxicos; da solubilidade do produto aplicado; e do período que a área permanece sem chuva após aplicação do produto (rainfastness). A partir do momento que atingem o solo, apresentam maior distribuição e persistência, devido aos canais formados pelos restos vegetais (formando vias preferenciais de escoamento) ou por organismos do solo (minhocas) e, principalmente, pelo abrandamento dos processos de degradação (Jones et al., 1990; Sorenson et al., 1991).

Cavenaghi et al. (2006) avaliaram a dinâmica do herbicida amicarbazone aplicado sobre diferentes quantidades de palha de canade-açúcar em diferentes intervalos de tempo e intensidades de chuva após aplicação do herbicida. Os resultados demonstraram que a quantidade de amicarbazone lixiviado pelas lâminas de água aplicadas variou conforme a quantidade de palha utilizada $(5,10,15 \mathrm{e}$ $\left.20 \mathrm{t} \mathrm{ha}^{-1}\right)$. Para $5 \mathrm{t}$ de palha ha ${ }^{-1}$, a lâmina de $2,5 \mathrm{~mm}$ lixiviou $40 \%$ do amicarbazone aplicado, enquanto para 10,15 e $20 \mathrm{t}_{\text {de }}$ palha $^{-1}$ a mesma lâmina lixiviou 33, 25 e $25 \%$ do amicarbazone aplicado, respectivamente, ou seja, as intensidades de palha iguais ou superiores a $5 \mathrm{t} \mathrm{ha}^{-1}$ apresentaram significativa interceptação do herbicida no momento da aplicação, 
reduzindo assim a transposição do amicarbazone na palha. Já o efeito das primeiras lâminas no processo de lixiviação para cada quantidade de palha foi mais intenso, retirando quantidades maiores do herbicida retido na palha, quando comparado às lâminas finais, em que o processo foi amenizado.

Segundo Toledo et al. (2004), o mecanismo de ação principal do amicarbazone é a inibição da fotossintese das plantas daninhas, atuando na reação de Hill (fotossistema II), inibindo o transporte de elétrons e paralisando a fixação de $\mathrm{CO}_{2}$ e a produção de ATP e NADPH2, os quais são elementos essenciais ao crescimento das plantas. A morte das plantas, entretanto, pode ocorrer devido a outros processos, como a peroxidação de lipídeos e proteínas, promovendo a destruição das membranas e perda de clorofila.

Assim, o objetivo deste trabalho foi avaliar a eficácia de amicarbazone em vaso quando aplicado em diferentes posicionamentos, em relação à camada de palha de cana-de-açúcar, e seu comportamento diante do efeito da chuva simulada antes ou após aplicação do herbicida.

\section{MATERIAL E MÉTODOS}

O experimento foi realizado no Núcleo de Pesquisas Avançadas em Matologia (NUPAM), pertencente ao Departamento de Produção Vegetal da Faculdade de Ciências Agronômicas/ UNESP - Botucatu/SP.

O solo utilizado foi inicialmente seco à sombra por um periodo de $48 \mathrm{~h}$, após o qual foi peneirado em peneira com malha de 200 mesh, e submetido às análises química (Tabela 1) e granulométrica, sendo classificado como solo de textura média; o solo foi adubado de acordo com o resultado da análise, para propiciar melhor germinação das plantas daninhas. Em seguida, o solo foi acondicionado em vasos de $2 \mathrm{~L}$ de capacidade, procedendo-se à semeadura com as es pécies Brachiaria plantaginea, Brachiaria decumbens, Ipomoea grandifolia e plantio dos tubérculos de Cyperus rotundus (15 tubérculos/vaso). O experimento foi conduzido em delineamento inteiramente casualizado, com quatro repetições, incluindose testemunhas sem o herbicida, com e sem a palha da cana-de-açúcar, para avaliação da eficácia agronômica do herbicida amicarbazone. A umidade do solo, medida gravimetricamente, foi mantida durante todo o ensaio em dois terços da capacidade de campo.

A quantidade de palha utilizada foi de $5 \mathrm{t} \mathrm{ha}^{-1}$, selecionada em função das informações disponiveis na literatura e de estudos anteriormente realizados, indicando ser essa quantidade uma das condições mais criticas em termos de manejo de plantas daninhas em cana-crua, uma vez que é insuficiente para controlar adequadamente as plantas daninhas, mas o bastante para reter quase que completamente a quantidade de calda aplicada (Velini $\&$ Negrisoli, 2000; Veiga Filho, 2002; Medeiros, 2002).

A pulverização do herbicida e a simulação de chuva foram realizadas através de um equipamento instalado em laboratório do NUPAM, o qual é constituído de uma estrutura metálica com $3 \mathrm{~m}$ de altura por $2 \mathrm{~m}$ de largura, que permite acoplamento de um "carrinho" suspenso a 2,5 $\mathrm{m}$ de altura. A esse carrinho encontram-se acopladas duas barras de pulverização, uma responsável pelo sistema de simulação de chuva e a outra pelo sistema de pulverização de defensivos agrícolas, as quais se deslocam por uma área útil de $6 \mathrm{~m}^{2}$ no sentido do comprimento do equipamento. $\mathrm{O}$ tracionamento de ambas as barras é realizado através de correntes e engrenagens, com auxílio de um motor elétrico, cujo ajuste é dado por um modulador de freqüência, permitindo a obtenção de velocidade constante previamente determinada. O sistema de pulverização tem funcionamento independente do sistema de simulação de chuva, apesar de ambos compartilharem o mesmo equipamento e funções de controle.

A simulação da chuva foi feita utilizandose uma bomba hidráulica de pressão constante e acionamento automático, a qual bombeia água armazenada de um reservatório, com capacidade para $1.000 \mathrm{~L}$, até a barra e pontas de pulverização responsáveis pela formação de gotas de chuva. A barra de simulação de chuva situada a 1,45 m de altura em relação à superficie das unidades experimentais é constituída por três bicos de pulverização TK-SS-20 de alta vazão, espaçados de $0,5 \mathrm{~m}$ e posicionados de forma a propiciar maior uniformidade 
Tabela 1 - Análise química do solo utilizado no experimento. Botucatu, 2003

\begin{tabular}{|c|c|c|c|c|c|c|c|c|c|c|}
\hline \multirow{2}{*}{ Solo } & \multirow{2}{*}{$\begin{array}{c}\mathrm{pH} \\
\left(\mathrm{CaCl}_{2}\right) \\
\end{array}$} & \multirow{2}{*}{$\begin{array}{l}\text { M.O. } \\
\left(\mathrm{g} \mathrm{dm}^{-3}\right)\end{array}$} & \multirow{2}{*}{$\begin{array}{c}\text { P }_{\text {res. }} \\
\left(\mathrm{mg} \mathrm{dm}^{-3}\right)\end{array}$} & \multicolumn{6}{|c|}{$\mathrm{mmol}_{\mathrm{c}}\left(\mathrm{dm}^{-3}\right)$} & \multirow{2}{*}{$\mathrm{V}(\%)$} \\
\hline & & & & $\mathrm{K}^{+}$ & $\mathrm{Ca}^{+2}$ & $\mathrm{Mg}^{+2}$ & $\mathrm{H}^{+}+\mathrm{Al}^{+3}$ & SB & $\mathrm{T}$ & \\
\hline $\mathrm{LVd}$ & 4,3 & 19 & 1 & 0,6 & 10 & 4 & 58 & 14,6 & 73 & 21 \\
\hline
\end{tabular}

Realizada pelo Departamento de Solos - FCA/UNESP - Botucatu.

de precipitação na área aplicada. Este sistema foi operado com velocidade de deslocamento de $0,187 \mathrm{~km} \mathrm{~h}^{-1}$, o que correspondeu a 2,5 Hertz no modulador de freqüência e pressão de trabalho de 0,81 kgf $\mathrm{s}^{2}$. Essas especificações proporcionaram a produção de gotas artificiais de chuva com diâmetro mediano volumétrico (DMV) de 1.140 micras, conforme informações do fabricante da ponta de pulverização (Spraying Systems Co.). Cada lâmina aplicada correspondeu a aproximadamente 2,5 mm de chuva.

A barra de pulverização é constituída por quatro pontas de pulverização XR 110.02 VS, espaçadas de $0,5 \mathrm{~m}$ e posicionadas a $0,5 \mathrm{~m}$ de altura em relação à superficie das unidades experimentais. Para as pulverizações do herbicida, o sistema foi operado com velocidade de deslocamento de $3,6 \mathrm{~km} \mathrm{~h}^{-1}$, o que correspondeu a 45,0 Hertz no modulador de freqüência, com consumo de calda de $200 \mathrm{~L} \mathrm{ha}^{-1}$. O equipamento foi operado sob pressão constante de 1,5 bar pressurizado por ar comprimido. A dose de amicarbazone foi de $1.400 \mathrm{~g} \mathrm{ha}^{-1}$.

Os tratamentos que foram conduzidos constaram de diferentes posicionamentos do herbicida e condições de umidade antes e após a aplicação. O tratamento 1 constou de cobertura de palha seca $\left(5 \mathrm{t} \mathrm{ha}^{-1}\right)$ sobre o solo seco antes da aplicação do herbicida, com simulação de uma chuva de $30 \mathrm{~mm}$ depois de 24 horas da aplicação; no tratamento 2, simulou-se uma chuva de $30 \mathrm{~mm}$ sobre o solo seco, antes da cobertura com a palha seca $\left(5 \mathrm{t} \mathrm{ha}^{-1}\right)$, e foi feita aplicação do herbicida após; o tratamento 3 constou do tratamento 2 , porém foi simulado um orvalho todos os dias pela manhã, até o final do ensaio; no tratamento 4, simulou-se uma chuva de $30 \mathrm{~mm}$ no solo seco antes da cobertura com palha seca ( $5 \mathrm{t} \mathrm{ha}^{-1}$ ) e a aplicação do herbicida foi feita em pós-emergência, quando as plântulas estavam com duas a quatro folhas (18 DAA dos demais tratamentos); no tratamento 5 foi realizada a chuva de $30 \mathrm{~mm}$ sobre o solo seco e aplicou-se o herbicida antes da cobertura com a palha seca $\left(5 \mathrm{t} \mathrm{ha}^{-1}\right)$; o tratamento 6 constou de cobertura do solo seco com a palha seca $\left(5 \mathrm{tha}^{-1}\right)$, sendo simulada uma chuva de $30 \mathrm{~mm} 12$ horas antes da aplicação do herbicida; no tratamento 7 foi feita a cobertura com palha seca sobre o solo seco ( $5 \mathrm{t} \mathrm{ha}^{-1}$ ) antes da aplicação do herbicida e realizou-se uma chuva de 2,5 $\mathrm{mm}$ logo após; o tratamento 8 constou da testemunha com palha seca (5 t ha-1) e sem aplicação; no tratamento 9 foi feita a aplicação em pré-emergência do herbicida em solo sem cobertura de palha; e o tratamento 10 constou da testemunha sem cobertura de palha e sem aplicação.

As porcentagens de controle obtidas nas avaliações foram correlacionadas com a escala de notas da "Asociación LatinoAmericana de Malezas" (ALAM, 1974), apresentada na Tabela 2, que atribui nota de controle, bem como o seu conceito, para cada classe de porcentagem estabelecida.

Foram realizadas avaliações visuais de controle das plantas daninhas aos $7,14,21$, 28, 35, 42, 49 e 56 dias após a aplicação (DAA) e peso da biomassa seca total aos 56 DAA (Tabela 3). O tratamento com aplicação em pósemergência foi iniciado aos 18 DAA dos demais tratamentos.

Além disso, coletaram-se 40 tubérculos de cada tratamento aos 56 DAA com o objetivo de verificar a viabilidade daqueles que se desenvolveram nos vasos. Para isso, foi utilizada uma metodologia com tetrazólio, segundo Silva et al. (2006).

O delineamento experimental utilizado foi o inteiramente casualizado, com 10 tratamentos e quatro repetições; os resultados foram submetidos à análise de variância pelo teste $\mathrm{F}$, sendo suas médias comparadas pelo teste $t$ a $10 \%$ de probabilidade. 
Tabela 2 - Escala da ALAM utilizada para avaliação da eficácia de controle de plantas daninhas

\begin{tabular}{|c|l|}
\hline $\begin{array}{c}\text { Classe de por centagem } \\
(\%)\end{array}$ & $\begin{array}{c}\text { Nota e conceito de } \\
\text { controle }\end{array}$ \\
\hline $0-40$ & $1-$ Nenhum a pobre \\
\hline $41-60$ & $2-$ Regular \\
\hline $61-70$ & $3-$ Suficiente \\
\hline $71-80$ & $4-$ Bom \\
\hline $81-90$ & $5-$ Muito Bom \\
\hline $91-100$ & $6-$ Excelente $(6)$ \\
\hline
\end{tabular}

Na condição em que o produto foi aplicado sobre a palha, em pré-emergência das plantas daninhas e sem simulação de chuva após aplicação (tratamento 2), o herbicida proporcionou bom controle de $I$. grandifolia aos 14 DAA (nota 4; 77\%) e excelente a partir de 21 DAA, tendo alcançado nota 6 (Tabela 4). Ainda nessa condição, a simulação diária de orvalho em quantidade correspondente a $0,3 \mathrm{~mm}$ de chuva (tratamento 3), provavelmente, precipitou a lixiviação do herbicida para o solo, verificandose, neste caso, excelente controle já aos 14 DAA (nota 6).

Tabela 3 - Peso da biomassa seca total (g), aos 56 DAA. Botucatu, 2003

\begin{tabular}{|c|c|c|c|c|}
\hline \multirow{2}{*}{ Tratamento* $^{*}$} & \multicolumn{4}{|c|}{ Peso da biomassa seca total (g) aos 56 DAA } \\
\cline { 2 - 5 } & IAQGR & BRAPL & BRADC & CYPRO \\
\hline 1 & $0 \mathrm{c}^{\mathrm{I}^{\prime}}$ & $0,00 \mathrm{c}$ & $0,00 \mathrm{e}$ & $0,13 \mathrm{~g}$ \\
\hline 2 & $0 \mathrm{c}$ & $3,49 \mathrm{~b}$ & $1,60 \mathrm{c}$ & $3,91 \mathrm{~cd}$ \\
\hline 3 & $0 \mathrm{c}$ & $3,64 \mathrm{~b}$ & $1,25 \mathrm{~cd}$ & $4,57 \mathrm{bc}$ \\
\hline 4 & $0 \mathrm{c}$ & $0,81 \mathrm{c}$ & $0,27 \mathrm{de}$ & $2,16 \mathrm{ef}$ \\
\hline 5 & $0 \mathrm{c}$ & $0,00 \mathrm{c}$ & $0,00 \mathrm{e}$ & $0,87 \mathrm{fg}$ \\
\hline 6 & $0,0 \mathrm{c}$ & $2,14 \mathrm{bc}$ & $1,42 \mathrm{~cd}$ & $2,89 \mathrm{de}$ \\
\hline 7 & $0,0 \mathrm{c}$ & $0,00 \mathrm{c}$ & $0,19 \mathrm{de}$ & $0,24 \mathrm{~g}$ \\
\hline 8 & $6,7 \mathrm{a}$ & $3,72 \mathrm{~b}$ & $5,18 \mathrm{~b}$ & $5,54 \mathrm{~b}$ \\
\hline 9 & $0,0 \mathrm{c}$ & $0,00 \mathrm{c}$ & $0,00 \mathrm{e}$ & $0,41 \mathrm{~g}$ \\
\hline 10 & $3,96 \mathrm{~b}$ & $9,60 \mathrm{a}$ & $7,29 \mathrm{a}$ & $8,70 \mathrm{a}$ \\
\hline CV $\%$ & 80,69 & 77,77 & 59,99 & 44,09 \\
\hline DMS & 1,033 & 2,185 & 1,241 & 1,558 \\
\hline
\end{tabular}

${ }^{1}$ Médias seguidas das mesmas letras não diferem estatisticamente entre si pelo teste t a $10 \%$ de probabilidade.

* 1. Palha + aplicação + chuva (24 horas); 2. Chuva + palha + aplicação; 3. Similar ao $2+$ orvalho diário; 4. Chuva + palha + aplicação pós-emergência com 2 a 4 folhas (18 DAA dos demais); 5. Chuva + aplicação + palha; 6. Palha + chuva + aplicação (12 horas); 7. Palha + aplicação + chuva $(2,5 \mathrm{~mm})$; 8 . Testemunha com palha; 9. Aplicação sem palha; 10. Testemunha sem palha. Obs.: IAQGR (Ipomoea grandifolia); BRAPL (Brachiaria plantaginea); BRADC (Brachiaria decumbens); CYPRO (Cyperus rotundus).

\section{RESULTADOS E DISCUSSÃO}

Nas Tabelas 4 e 5 são apresentadas as porcentagens médias de controle e suas respectivas notas, para as diferentes espécies e épocas de avaliação.

Para I. grandifolia (Tabela 6), todos os tratamentos apresentaram excelente nivel de controle, obtendo nota 6 , desde 35 DAA. Nessa espécie, os sintomas de intoxicação foram observados logo aos $7 \mathrm{DAA}$, exceto quando o amicarbazone foi aplicado em pós-emergência, no estádio inicial de desenvolvimento da planta daninha (2-4 folhas).
No tratamento 4, em que o amicarbazone foi aplicado em pós-emergência da planta daninha (2-4 folhas), o produto apresentou $50 \%$ de controle da espécie desde a avaliação realizada aos 3 DAA. Os sintomas de intoxicação rapidamente evoluíram, tendo alcançado excelente nivel de controle (nota 6) na avaliação seguinte, realizada aos 10 DAA, mantendo esse patamar até a ultima avaliação, feita aos 38 DAA. No tratamento 6, em que o herbicida foi aplicado sobre palha úmida, o amicarbazone também alcançou niveis mais elevados de controle durante a condução do ensaio, atingindo nota 5 $(87,5 \%)$ aos 28 DAA, e excelente entre os 35 e 

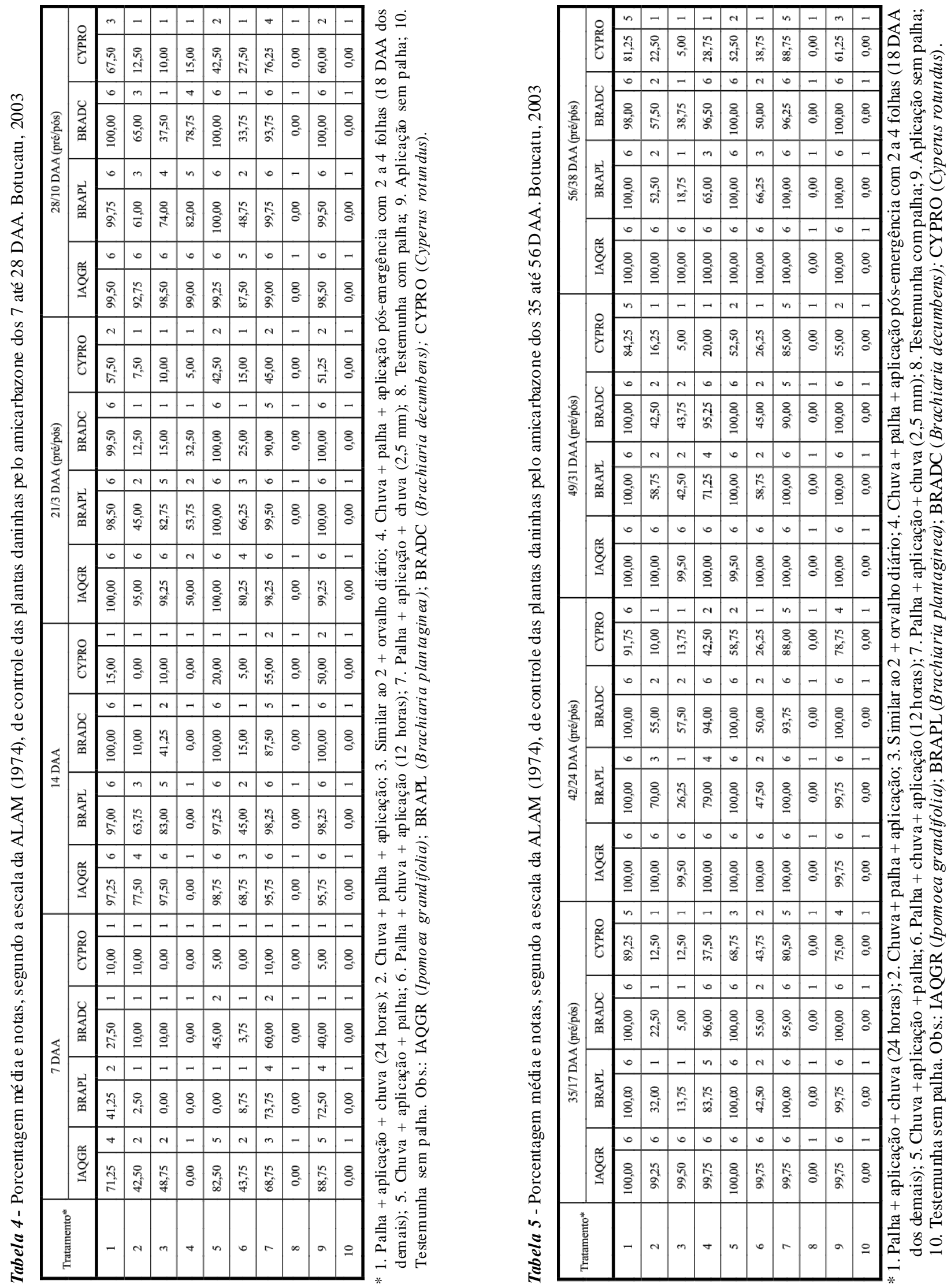
56 DAA (nota 6). Negrisoli et al. (2004) também observaram que a aplicação de sulfentrazone sobre a palha de cana-de-açúcar resultou em excelente controle $(100 \%$ aos 28 dias após a aplicação) da espécie I. grandifolia, quando ocorre chuva de $20 \mathrm{~mm}$ um dia após a aplicação.

Com relação a $B$. plantaginea (Tabelas $4 \mathrm{e}$ $5)$, os melhores tratamentos observados foram aqueles em que o herbicida foi aplicado diretamente no solo desnudo, e assim mantido durante o experimento (tratamento 5), e aquele em que o solo foi recoberto com de $5 \mathrm{t} \mathrm{ha}^{-1} \mathrm{de}$ palha (tratamento 9), além dos tratamentos em que o herbicida foi aplicado diretamente sobre a palha, recebendo após a aplicação do amicarbazone uma precipitação correspondente a 2,5 $\mathrm{mm}$ (tratamento 7) ou $30 \mathrm{~mm}$ (tratamento 1). A condição em que o produto foi aplicado sobre a palha e sem simulação de chuva após a aplicação (tratamento 2) chegou a proporcionar controle suficiente (nota 3) aos 42 DAA, tendo, porém, reduzido aos 56 DAA, quando se verificou nível de controle regular (nota $2 ; 52,5 \%$ ). Já para o tratamento 3 , com aplicação diária de orvalho sobre a palha, a eficácia do herbicida diminuiu a partir dos 28 DAA, atingindo aos 56 DAA nota $1(18,75 \%)$. No tratamento 6 , em que se aplicou o produto em palha úmida, o nível de controle foi inferior a $66,25 \%$ (nota 3). Na condição em que o amicarbazone foi aplicado em pós-emergência da planta daninha (tratamento 4), o herbicida apresentou nivel de controle de 50\% aos 3 DAA, havendo incremento de eficácia para conceito muito bom aos 10 e 17 DAA (83\%; nota 5), tendo, porém, ocorrido diminuição do nível de controle para bom nas avaliações feitas aos $24 \mathrm{e}$ 31 DAA (nota 4) e suficiente aos 38 DAA (nota 3 ).

No que se refere a $B$. decumbens (Tabelas 4 e 5), os tratamentos mais eficazes foram aqueles em que o herbicida foi aplicado diretamente no solo e mantido sem recobrimento com palha durante o experimento (tratamento 9) ou recoberto com quantidade correspondente a $5 \mathrm{t} \mathrm{ha}^{-1}$ de palha (tratamento 5 ), bem como o tratamento em que o herbicida foi aplicado sobre a palha, recebendo após a aplicação uma precipitação correspondente a $30 \mathrm{~mm}$ (tratamento 1). Esses tratamentos apresentaram excelente nivel de controle desde 14 DAA, e assim permaneceram até 56 DAA (nota 6). No tratamento 7 , em que o herbicida foi aplicado sobre a palha simulando-se em seguida uma chuva de $2,5 \mathrm{~mm}$, e no tratamento 4 , em que o herbicida foi aplicado em pós-emergência, também houve controle excelente (nota 6) aos 56 e 31 DAA, respectivamente, mas com evolução mais lenta dos sintomas de intoxicação quando comparados aos tratamentos 1, 5 e 9 . Os tratamentos 2 (com aplicação sobre a palha e sem chuva), 3 (com simulação diária de orva1ho) e 6 (com aplicação do amicarbazone sobre a palha úmida) foram os que apresentaram os menores indices de controle da espécie, quando comparados aos demais. Nesses casos, as porcentagens máximas de controle foram de $65 \%$ aos 28 DAA para o tratamento 2 (nota 3 - suficiente), $57,5 \%$ aos 42 DAA para o tratamento 3 (nota 2 - regular) e $55 \%$ aos 35 DAA para o tratamento 6 (nota 2 - regular).

Para a espécie C. rotundus (Tabelas 4 e 5 ), os tratamentos mais eficazes foram aqueles em que o amicarbazone foi aplicado diretamente sobre a palha, simulando-se em seguida uma precipitação correspondente a $30 \mathrm{~mm}$ (tratamento 1) ou $2,5 \mathrm{~mm}$ (tratamento 7 ). A maior porcentagem de controle alcançada no tratamento 1 foi de $91,75 \%$ aos 42 DAA (nota 6), retrocedendo para $81,25 \%$ aos 56 DAA (nota 5). Já no tratamento 7 , a maior porcentagem de controle foi de $88,75 \%$ aos 56 DAA (nota 5). Contudo, nos tratamentos em que o amicarbazone foi aplicado diretamente sobre o solo, com cobertura de palha após a aplicação (tratamento 5) e sem cobertura de palha (tratamento 9), as porcentagens máximas observadas foram, respectivamente, de $68,75 \%$ aos 35 DAA (nota 3 ) e de $78,75 \%$ aos 42 DAA (nota 4). Nos demais tratamentos, a porcentagem de controle apresentou-se sempre abaixo de $45 \%$.

Independentemente da planta daninha estudada, os tratamentos 1, 5, 7 e 9 foram os que apresentaram as maiores porcentagens médias de controle aos 56 DAA, provavelmente pelo fato de que, nesses tratamentos, o amicarbazone tenha atingido o solo através da aplicação direta ou através da lixiviação do herbicida, promovida pela simulação da chuva após sua aplicação.

Na Tabela 6 são apresentados os resultados obtidos para peso da matéria seca de cada planta daninha, avaliada nos diferentes 
Tabela 6 - Porcentagem de tubérculos de C. rotundus, viáveis e inviáveis, obtidos pelo teste de tetrazólio. Botucatu, 2003

\begin{tabular}{|c|c|c|}
\hline Tratamento* & $\begin{array}{c}\text { Tubérculo } \\
\text { inviável }(\%)\end{array}$ & $\begin{array}{c}\text { Tubérculo } \\
\text { viável }(\%)\end{array}$ \\
\hline 1 & 75,0 & 25,0 \\
\hline 2 & 2,5 & 97,5 \\
\hline 3 & 0,0 & 100,0 \\
\hline 4 & 10,0 & 90,0 \\
\hline 5 & 30,0 & 70,0 \\
\hline 6 & 3,1 & 96,9 \\
\hline 7 & 37,5 & 62,5 \\
\hline 8 & 2,5 & 97,5 \\
\hline 9 & 48,9 & 51,1 \\
\hline 10 & 2,5 & 97,5 \\
\hline
\end{tabular}

* 1. Palha + aplicação + chuva (24 horas); 2. Chuva + palha + aplicação; 3. Similar ao $2+$ orvalho diário; 4 . Chuva + palha + aplicação pós-emergência com 2 a 4 folhas (18 DAA dos demais); 5. Chuva + aplicação + palha; 6 . Palha + chuva + aplicação (12 horas); 7. Palha + aplicação + chuva $(2,5 \mathrm{~mm}) ; 8$. Testemunha com palha; 9. Aplicação sem palha; 10. Testemunha sem palha.

tratamentos, aos 56 ou 38 DAA. Pela análise dessa tabela, pode-se observar que, para I. grandifolia, todos os tratamentos com o amicarbazone resultaram na eliminação da biomassa da espécie. Já para B. plantaginea, somente os tratamentos $1,5,7$ e 9 proporcionaram essa eliminação. Apesar de os tratamentos 4 (em que o amicarbazone foi aplicado em pós-emergência) e 6 (aplicação do herbicida em palha úmida) não terem eliminado a biomassa da planta daninha, eles não diferiram estatisticamente dos demais tratamentos com o herbicida. Por sua vez, os tratamentos 2 (aplicação em palha seca e sem chuva após) e 3 (orvalho diário) não diferiram estatisticamente da biomassa seca obtida para a testemunha com palha (tratamento 8). Rossi et al. (2004), estudando a associação do metribuzin com palha de cana-de-açúcar na eficácia de controle de plantas daninhas, observaram que o produto foi eficaz em todos os posicionamentos, quando associado à palha de cana-deaçúcar.

Para $B$. decumbens, os tratamentos $1,5 \mathrm{e}$ 9 resultaram na eliminação da biomassa das plantas; apesar de os tratamentos 4 e 7 não terem reduzido completamente a biomassa das plantas, não diferiram estatisticamente dos tratamentos supracitados. Os tratamentos 2 , 3 e 6 apresentaram maior peso de $B$. decumbens, em relação aos anteriores, embora também tenham reduzido sua biomassa, uma vez que diferiram estatisticamente da testemunha com palha.

Em relação a $C$. rotundus, os tratamentos 1 e 7 foram os que mais reduziram a biomassa da planta daninha, porém sem diferirem estatisticamente dos tratamentos 5 e 9 . Nos demais tratamentos também houve redução da biomassa, visto que diferiram estatisticamente das testemunhas. Analisando os tubérculos obtidos em cada tratamento (Tabela 6), para o teste com tetrazólio $(0,01 \%$ por $48 \mathrm{~h})$, verificouse que, na situação em que o herbicida foi aplicado sobre a palha e recebeu chuva de $30 \mathrm{~mm}$ após a aplicação (tratamento 1), somente $25 \%$ dos tubérculos apresentavam-se viáveis. A umidade propiciada pela simulação de $30 \mathrm{~mm}$ chuva, bem como a lixiviação do produto para o solo, ocorrendo no mesmo momento, provavelmente favoreceram a eficácia do amicarbazone no controle da espécie.

As testemunhas com palha (tratamento 8) e sem palha (tratamento 10) diferiram estatisticamente em todas as espécies estudadas. Enquanto a cobertura com palha provocou estímulo na germinação de $I$. grandifolia, sua presença causou efeito supressivo na germinação das demais espécies avaliadas $(B$. plantaginea, $B$. decumbens e $C$. rotundus).

Dessa forma, pode-se concluir que a espécie I. grandifolia mostrou-se mais sensivel ao amicarbazone, demonstrando elevada sensibilidade aos tratamentos com herbicidas. Para $B$. plantaginea e $B$. decumbens, as porcentagens de controle foram altas nos tratamentos em que o herbicida atingiu o solo (tratamento 1, 5, 7 e 9), independentemente se aplicado diretamente sobre este ou lixiviado pela simulação de chuva após a aplicação do herbicida, fato esse explicado por Toledo et al. (2004), os quais relatam que o amicarbazone é absorvido pelo sistema radicular e translocado via xilema; no entanto, quando aplicado em pós-emergência, predomina a absorção foliar, sendo sua ação de contato.

Já para C. rotundus, as maiores porcentagens de controle foram observadas quando o herbicida foi aplicado sobre a palha, recebendo 2,5 ou $30 \mathrm{~mm}$ de chuva após a aplicação. 


\section{LITERATURA CITADA}

ASOCIACIÓN LATINOAMERICANA DE MALEZAS ALAM. Recomendaciones sobre unificación de los sistemas de evaluación en ensayos de control de malezas. ALAM, v. 1 , n. 1, p. 35-38, 1974.

CAVENAGHI, A. L. et al. Performance do herbicida Dinamic aplicado sobre a palha de cana-de-açúcar. In: CONGRESSO BRASILEIRO DA CIÊNCIA DAS PLANTAS

DANINHAS, 25., 2006, Brasília-DF. Resumos... Brasília: Sociedade Brasileira da Ciência das Plantas Daninhas, 2006. CD-ROM.

CORREA, N. M.; DURIGAN, J. C. Emergência de plantas daninhas em solo coberto com palha de cana-de-açúcar.

Planta Daninha, v. 22, n. 1, p. 11-17, 2004.

JONES JR, R. E.; BANKS, P. A.; RADCLIFFE, D. E. Alachlor and metribuzin movement and dissipation in a soil profile as influenced by soil surface condition. Weed Sci., v. 38, p. 589-597, 1990.

LAMOREAUX, R. J.; JAIN, R.; HESS, F. D. Efficacy of dimethenamid, metolachlor and encapsulated alachlor in soil covered with crop residue. Bringhton Crop Protec. Conf. - Weeds, v. 3, p. 1015-1020, 1993.

LOCKE, M. A.; BRYSON, C. T. Herbicide-soil interaction in reduced tillage and plant residue management systems. Weed Sci., v. 45, p. 307-20, 1997.

MANECHINI, C. Manejo da cana crua. In: SEMINÁRIO COPERSUCAR DE TECNOLOGIA AGRONÔMICA, 7., 1997, Piracicaba. Anais... Piracicaba: 1997. p. 309-327.

MARTINS, D. et al. Emergência em campo de dicotiledôneas infestantes em solo coberto com palha de cana-de-açúcar. Planta Daninha, v. 17, n. 1, p. 151-161, 1999.
NEGRISOLI, E. et al. Eficácia do sulfentrazone em diferentes doses associado à palha de cana-de-açúcar com ou sem chuva após a aplicação no controle de plantas daninhas. In: CONGRESSO BRASILEIRO DA CIÊNCIA DAS PLANTAS DANINHAS, 24., 2004, São Pedro. Anais... São Pedro: 2004. $150 \mathrm{p}$.

ROSSI, C. V. S. Dinâmica e eficácia no controle de plantas daninhas pelo herbicida metribuzin aplicado sobre palha de cana-de-açúcar. 2004. 95 f. Dissertação (Mestrado em Agronomia/Proteção de Plantas) Universidade Estadual Paulista, Botucatu, 2004.

SILVA, F. M. L.; VELINI, E. D.; ROSSI, C. V. S. Desenvolvimento de metodologia para determinar a viabilidade de tubérculos de Cyperus rotundus com uso de tetrazólio. In: CONGRESSO BRASILEIRO DA CIÊNCIA DAS PLANTAS DANINHAS, 25., 2006, Brasília. Resumos... Brasília: SBCPD/UnB, 2006.

SORENSON, B.A.; SHEA, P.J.; ROETH, F.W. Effects of tillage, application time and rate on metribuzin dissipation. Weed Res., v.31, p. 333-345, 1991.

TOLEDO, R. E. B. et al. Dinamic (Amicarbazone), novo herbicida seletivo para o controle de plantas daninhas em pré e pós emergência na cultura da cana-de-açúcar. In: CONGRESSO BRASILEIRO DA CIÊNCIA DAS PLANTAS DANINHAS, 24., 2004, São Pedro. Resumos... São Pedro: 2004. 245 p.

VELINI, E.D.; NEGRISOLI, E. Controle de plantas daninhas em cana crua. In: CONGRESSO BRASILEIRO DA CIÊNCIA DAS PLANTAS DANINHAS, 22., 2000, Foz de Iguaçu. Palestras... Foz de Iguaçu: 2000. p.148-164. 